\title{
Cancer incidence in eastern Morocco: cancer patterns and incidence trends, 2005-2012
}

Manal Elidrissi Errahhali ${ }^{\dagger}$, Mounia Elidrissi Errahhali ${ }^{\dagger}$, Meryem Ouarzane, Redouane Boulouiz and Mohammed Bellaoui ${ }^{*}$

\begin{abstract}
Background: Cancer is one of the major health problems worldwide. In this article, we present for the first time the cancer incidence trends, the distribution and the socioeconomic profile of incident cancer cases in Eastern Morocco over a period of eight years.
\end{abstract}

Methods: Retrospective descriptive study of patients diagnosed with cancer at the Hassan II Regional Oncology Center (ROC) since it was created in October 2005 until December 2012. During the study period, the ROC was the only hospital specialized in cancer care in Eastern Morocco.

Results: A total of 7872 incident cases of cancer were registered in Eastern Morocco. Among these incident cases 5220 cases were women and 2652 were men, with a female to male ratio of 1.97. The mean age at diagnosis was 58 years for males and 52 for females and $94 \%$ of the patients aged over 30 years. For both sexes combined and for all cancer sites, breast cancer was the commonest followed by cervix uteri, colon-rectum, lung, nasopharynx, and stomach cancers. The most common cancer in women was breast cancer, followed respectively by cervix uteri cancer, colonrectum cancer, ovary cancer, and stomach cancer. In men, the lung cancer ranked first, followed respectively by colonrectum cancer, nasopharynx cancer, prostate cancer, and stomach cancer. For most cancers, crude incidence rates (CR) have increased significantly. The CR for all cancers combined has increased from 56.6 to 80.3 per 100,000 females and from 32.3 to 42.6 per 100,000 males during the study period. Patients profile analysis showed that $79 \%$ of cancer patients were from urban areas, $83 \%$ were unemployed and $85 \%$ had no health insurance.

Conclusions: The distribution of cancers in Eastern Morocco is different from those observed in other regions of Morocco. Unlike most countries, women were much more affected with cancer than men in Eastern Morocco. More importantly, the rates of many cancers are rising. Therefore, our data justify the need to develop effective programs for cancer control and prevention in Eastern Morocco. A better access to cancer care should be a priority of the health policies, given that the majority of cancer patients in Eastern Morocco are unemployed, and do not have medical care coverage.

Keywords: Cancer patterns, Incidence, Time trends, Cancer control, Morocco

\footnotetext{
* Correspondence: bmbellaoui@gmail.com

${ }^{\dagger}$ Equal contributors

Genetics Unit, Faculty of Medicine and Pharmacy of Oujda, University

Mohammed Premier, Oujda, Morocco
} 


\section{Background}

According to WHO estimates, cancer causes more deaths than all cardiovascular diseases [1]. Therefore, cancer has become a major public health problem worldwide $[2,3]$. The most common tumors worldwide were lung cancer with 1.8 million cases (13.0\% of total), breast cancer with 1.7 million cases (11.9\% of total) and the colorectal cancer with 1.4 million cases $(9.7 \%$ of total). Similarly, cancers that cause the highest rate of deaths are cancers of the lung (1.6 million deaths, $19.4 \%$ of total), liver ( 0.8 million deaths, $9.1 \%$ of total) and stomach ( 0.7 million deaths, or $8.8 \%$ of total) [1]. In 2012, the overall cancer burden reached 14.1 million new cases compared to 12.7 million in 2008 [4, 5]. Similarly, 8.2 million deaths have been attributed to cancer during 2012 (13\% of all deaths worldwide) compared to 7.6 million deaths in 2008 [4, 5].

In 2012, more than half of all cancer cases (56.8\%) and deaths caused by cancer (64.9\%) were recorded in the least developed regions of the world [1]. For example in Africa, there were 846,961 cases of cancer and 591,161 cancer deaths in 2012 [1]. Accordingly, epidemiologic studies predict 1.2 million new cancer cases in Africa with more than 970,000 deaths by 2030 if adequate control and prevention measures are not taken promptly $[1,6]$.

In Morocco, cancer is a major health problem and it is the second leading cause of mortality after cardiovascular diseases with $10.7 \%$ of all deaths [7]. However, there are only two population-based cancer registries in Morocco at the present time. The Casablanca registry was founded in March 2003 and the Rabat registry was created in January 2005. These registries have provided important information on cancer patterns in western Morocco [8-12]. In Eastern Morocco, nothing is known about cancer incidence and therefore, in this study, we report for the first time the cancer incidence trends, the distribution and the socioeconomic profile of incident cancer cases in Eastern Morocco over a period of eight years between 2005 and 2012.

\section{Methods}

\section{Setting}

Eastern Morocco is located in the north east of the kingdom of Morocco. According to the High Commission for Planning (HCP), Eastern Morocco had a population of over 2 million in 2013, which is equivalent to $6.2 \%$ of the total population of the Kingdom. The population is mainly urban (67\% vs. $33 \%$ rural) and young, nearly 6 out of 10 people are under 30 years [13-16].

Our retrospective study was based on all incident cases that were registered at the Hassan II Regional Oncology Center, since it was created in October 2005 until December 2012. During the study period, the Hassan II Regional Oncology Center (ROC) was the only health care facility for management of all solid cancer cases among adult patients in Eastern Morocco.While during this period, childhood cancer cases were treated in other health care facilities in the capital of Morocco (Rabat). However, hematological malignancies (HM) were managed in different centres: Al-Farabi Regional Hospital, Boussif Diagnostic Center, ROC, and some health care facilities in Rabat $[13,15]$.

\section{Data collection and cancer classification}

The data were collected from patient medical records, pathology records and admission records. The registrations are considered microscopically verified when the diagnosis is based on a malignant histological or cytological reports. The majority $(98 \%)$ of the cases were microscopically verified. We excluded from the study patients for whom the proof of cancer could not be made or the medical file is incomplete or unexploitable. The borderline tumors and cases of intraepithelial neoplasia were also excluded from the study. Patients who do not reside in Eastern Morocco or for whom the place of residence was not specified were also excluded from the analysis.

We followed the registration rules, defined by the International Agency for Research on Cancer (IARC). The registered cases were coded according to the third edition of the International Classification of Diseases for Oncology (ICD-O-3) [17]. For tabulation of results, these were converted to the 10th revision of the ICD-O [18]. A form has been used for collecting information recorded on each case, such as the record number, name and surname of the patient, gender, age, family status, occupation, place of residence, health insurance, basis of diagnosis, tumor site and histology, incident date, and age at diagnosis. Gender has been indicated for all cases reported to the Hassan II Regional Oncology Center during the period of the study. However, age was not reported for $2.07 \%$ of men and $2.35 \%$ of women.

\section{Analysis}

Data collection was performed on Excel. Statistical analysis was performed using SPSS software version 21.0. Crude incidence rates (CR) and Age-specific incidence rates (Ai) were calculated as previously described [19, 20]. The rates were expressed per 100,000 person per year [21]. Incidence cases which were registered during the period between January 2006 and December 2012 were used for the calculation of the incidence rates. $\mathrm{Na}$ tional population censuses are conducted in Morocco every 10 years, and the HCP provides estimates of the growth rate of the Moroccan population for each year. In this paper, the census conducted in 2004 was used to elaborate the estimates of the population of Eastern Morocco during the period from 2006 to 2012. The annual percent change (APC) was calculated as previously described $[21,22]$ using the formula: $\mathrm{APC}=[\exp (\beta)-$ 
$1] \times 100$, where $\beta$ is the parameter estimate obtained on fitting period of event as a continuous variable to the logarithm of the rate. For the Chi-squared test, the results are considered significant when $\mathrm{p}$ (degree of significance) is less than 0.05 , very significant when $p<0.01$ and highly significant when $p<0.001$.

\section{Results}

\section{Cancer profiles in eastern Morocco}

A total of 7872 incident cases of cancer were registered at the Hassan II Regional Oncology Center (ROC) since it was created in October 2005 until December 2012. Of these, 5220 cases were women and 2652 were men, with a female to male ratio of $1.97(p<0.001)$ (Table 1$)$. The mean age at diagnosis was 58 years for males and 52 for females and $94 \%$ of the patients aged over 30 years.

The distribution of cancers in our study is shown in Table 2. Breast cancer came first, and exceeded by far the other cancers, with $30.75 \%$ of all cancers. The cervix uteri cancer came in the second position with $9.10 \%$, followed respectively by colon-rectum cancer $(8.16 \%)$, lung cancer (7.53\%), nasopharyngeal cancer (5.03\%), and stomach cancer with $4.43 \%$ (Table 2 ).

The gynecological and breast cancers (combined) are the most common tumors with $44.14 \%$ of all cancers, followed respectively by digestive cancers $(16.9 \%)$, head and neck cancers (8.1\%), and thoracic cancers (7.66\%). Breast cancer occupies the first place in the gynecological and breast cancers with $69.66 \%$, followed respectively by cervix uteri cancer $(20.6 \%)$, ovarian cancer $(5.65 \%)$ and corpus uteri cancer $(2.15 \%)$. Regarding digestive cancers, colon-rectum cancer was in the first position with $48.34 \%$, followed respectively by stomach cancer $(26.28 \%)$, esophageal cancer $(7.07 \%)$, pancreatic cancer $(6.69 \%)$, cancer of the gallbladder $(5.8 \%)$, liver cancer (4.44\%) and cancer of the small bowel (1.02\%).

Table 1 Female to male ratio of all incident cancer cases in Eastern Morocco as compared to other studies

\begin{tabular}{llll}
\hline Studies & Female cases & Male cases & F/H \\
\hline This study & 5220 & 2652 & 1.97 \\
Morocco. Fez [25] & 2622 & 2910 & 0.90 \\
Morocco. Rabat [10] & 1232 & 1241 & 0.99 \\
Morocco. Casablanca [12] & 6372 & 5551 & 1.14 \\
Tunisia [22] & 2474 & 3203 & 0.77 \\
Egypt [24] & 57425 & 57558 & 0.99 \\
China [21] & 18418 & 33515 & 0.54 \\
France [23] & 135895 & 183485 & 0.74 \\
European Union [1] & 1206 & 1430 & 0.84 \\
USA [1] & 779 & 825 & 0.94 \\
\hline
\end{tabular}

F/M sex ratio-female cases/male cases
Table 2 Distribution of the 7,872 incident cases by cancer type, October 2005-December 2012

\begin{tabular}{|c|c|c|c|c|}
\hline Type of cancer & Female & Male & Total & $\%$ \\
\hline All incident cases & 5220 & 2652 & 7872 & 100 \\
\hline Breast & 2368 & 53 & 2421 & 30.75 \\
\hline Cervix uteri & 716 & - & 716 & 9.1 \\
\hline Colon-rectum & 333 & 309 & 642 & 8.16 \\
\hline Lung & 90 & 503 & 593 & 7.53 \\
\hline Nasopharynx & 153 & 243 & 396 & 5.03 \\
\hline Stomach & 164 & 185 & 349 & 4.43 \\
\hline Skin & 109 & 145 & 254 & 3.23 \\
\hline Prostate & - & 220 & 220 & 2.79 \\
\hline Ovary & 197 & - & 197 & 2.5 \\
\hline Brain & 77 & 94 & 171 & 2.17 \\
\hline Bladder and urinary tract & 33 & 126 & 159 & 2.02 \\
\hline Bone & 62 & 70 & 132 & 1.68 \\
\hline Thyroid & 99 & 23 & 122 & 1.55 \\
\hline Esophagus & 42 & 52 & 94 & 1.19 \\
\hline Pancreas & 48 & 43 & 91 & 1.16 \\
\hline larynx & 12 & 78 & 90 & 1.14 \\
\hline Gallbladder & 67 & 12 & 79 & 1 \\
\hline Oral cavity and oropharynx & 39 & 37 & 76 & 0.97 \\
\hline Corpus uteri & 75 & - & 75 & 0.95 \\
\hline Soft parts & 32 & 42 & 74 & 0.94 \\
\hline Liver & 35 & 24 & 59 & 0.75 \\
\hline Kidney & 19 & 24 & 43 & 0.55 \\
\hline Peritoneum & 28 & 11 & 39 & 0.5 \\
\hline Vulva & 32 & - & 32 & 0.41 \\
\hline Salivary gland & 11 & 19 & 30 & 0.38 \\
\hline Eye & 10 & 13 & 23 & 0.29 \\
\hline Testicles & - & 20 & 20 & 0.25 \\
\hline Pharynx (unspecified) & 8 & 9 & 17 & 0.22 \\
\hline Small intestine & 10 & 4 & 14 & 0.18 \\
\hline Vagina & 10 & - & 10 & 0.13 \\
\hline Tonsil & 0 & 5 & 5 & 0.06 \\
\hline Mediastinum & 1 & 3 & 4 & 0.05 \\
\hline Pleura & 2 & 1 & 3 & 0.04 \\
\hline Trunk & 1 & - & 1 & 0.01 \\
\hline Penis & - & 1 & 1 & 0.01 \\
\hline Other & 337 & 283 & 620 & 7.88 \\
\hline
\end{tabular}

$\%$ percentage of the 7,872 incident cases; $\mathrm{N}$ number of incident cases

In women, breast cancer was almost half of female cancers with $45.36 \%$ of cases, and with a mean age at diagnosis of 48.7 years \pm 11.4 . The cervix uteri came in the second position with $13.72 \%$, followed respectively by colon-rectum cancer (6.38\%), ovarian cancer (3.77\%), and stomach cancer 
$(3,14 \%)$ (Fig. 1). In men, lung cancer was the most frequent malignancy with $19 \%$ of male cancers, followed respectively by colon-rectum cancer (11.65\%), nasopharyngeal cancer (9.16\%), prostate cancer $(8.3 \%)$, and stomach cancer $(7 \%)$ (Fig. 1). In our study, we found that men were more affected by lung cancer than women, with a male to female ratio of 5.6. The difference between sexes was highly significant $(p<0.001)$. Nasopharyngeal cancer affects both men and women but with a male to female ratio of $1.6(p<0.001)$, and the mean age for both sexes was 46 years.

\section{Trends in crude incidence rates in eastern Morocco}

The crude incidence rates (CR) by sex of all cancers combined and of the major cancers were calculated for each year from 2006 to 2012 (Table 3) and the trends in CR were presented in three time periods: 2006-2007, 2008-2010 and 2011-2012 (Fig. 2). In women, the CR of all cancers combined increased throughout the study. The rates rose from 56.6 to 80.3 per 100,000 between 2006 and 2012 at an annual rate (APC) of $6 \%$ (Table 3, Fig. 2). The CR for breast cancer increased significantly during the period 2006 to 2012 at an APC of 8.1\% (Table 3, Fig. 2). For colon-rectum and ovarian cancers, a significant increase was also observed at an APC of $18.7 \%$ and $9.9 \%$ respectively. However, the CR for cervix uteri cancer increased slightly by $1.6 \%$ during the study period, and that of the nasopharynx was decreasing (Table 3, Fig. 2).

In men, the $\mathrm{CR}$ for all cancers combined increased throughout the study. The rates rose from 32.3 to 42.6 per 100,000 between 2006 and 2012 at an APC of 4.7\% (Table $3)$. For lung, colon-rectum, and prostate cancers, there is a significant increase in CR between 2006 and 2012 by $9 \%$, $11 \%, 5.6 \%$ and $20 \%$ respectively (Table 3 , Fig. 2 ). However, $\mathrm{CR}$ for nasopharynx cancer significantly decreased between 2006 and 2012 by 10.6\% (Table 3, Fig. 2).

\section{Age-specific incidence rates of nasopharynx cancer in eastern Morocco}

The age-specific incidence rate of nasopharynx cancer in male has shown a bimodal distribution with a first small peak in children (15-19 years), and a second large peak at the age group 50-59 years (Fig. 3). After this second peak, the incidence declined in the older age groups. The incidence rate showed a strong decrease at the age group 60-69, probably due to the age during admission being reported in round numbers in the older age groups. Indeed, an equivalent decrease was noticed at this age group for most cancers analyzed. In women, the incidence rate increased gradually with age until it reached a peak in the 55-64 age groups, and then declined in the older age groups. Several differences were observed between men and women: the incidence was higher in men than in women. The highest age-specific incidence rate was observed in a slightly later age group in female than in male (55-64 age groups versus 50-59 respectively). More importantly, the first peak observed in male children was absent in female children (Fig. 3).

\section{Socioeconomic profile of incident cancer cases in eastern Morocco}

To improve the management of cancer patients and to plan and develop programs for cancer control and prevention in a region, it is very important to know its socio-economic context. Therefore, we have analyzed the profile of incident cancer cases registered at the $\mathrm{Re}$ gional Oncology Center. As shown in Tables 4, 79\% of cancer patients came from urban areas and $21 \%$ from rural areas $(p<0.001)$. The majority of the patients were unemployed ( $83 \%$ of cases), followed respectively by the following categories: retired (5\%), self-employed (4.2\%), employed (3.5\%), farmer (1.8\%), students $(1.1 \%)$, and
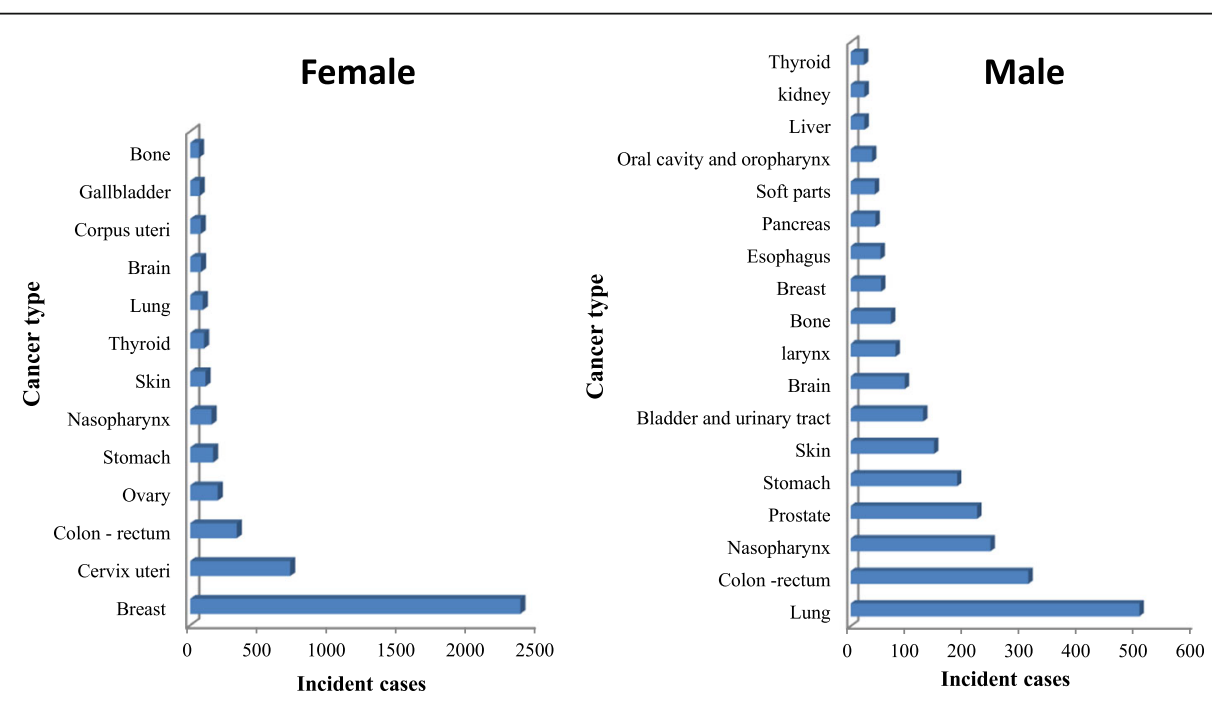

Fig. 1 Distribution of incident cases by cancer type and by sex in Eastern Morocco 
Table 3 Crude incidence rates of the major cancers in Eastern Morocco, 2006-2012

\begin{tabular}{|c|c|c|c|c|c|c|c|c|c|}
\hline \multirow[t]{2}{*}{ Type of cancer } & \multirow[t]{2}{*}{ ICD-10 } & \multicolumn{7}{|l|}{$C R$} & \multirow{2}{*}{$\begin{array}{l}\text { APC } \\
2006-2012\end{array}$} \\
\hline & & 2006 & 2007 & 2008 & 2009 & 2010 & 2011 & 2012 & \\
\hline \multicolumn{10}{|l|}{ Female } \\
\hline All cancers & COO-C90 & 56.6 & 64.5 & 68.5 & 61.3 & 70.9 & 81.6 & 80.3 & $+6 \%$ \\
\hline Breast & C50 & 23 & 27.6 & 35.8 & 27 & 31.2 & 35.2 & 36.8 & $+8.1 \%$ \\
\hline Cervix uteri & C53 & 9.2 & 10.6 & 11.2 & 7.4 & 8.9 & 9 & 10.1 & $+1.6 \%$ \\
\hline Colon-rectum & C18-C20 & 2 & 3.9 & 3 & 4.2 & 4.9 & 6.5 & 5.6 & $+18.7 \%$ \\
\hline Ovary & C56 & 1.7 & 2.9 & 2.4 & 2.5 & 2.7 & 3.3 & 3 & $+9.9 \%$ \\
\hline Nasopharynx & C11 & 2.4 & 2.3 & 1.8 & 1.2 & 1.5 & 1.7 & 1.5 & $-7.3 \%$ \\
\hline \multicolumn{10}{|l|}{ Male } \\
\hline All cancers & CoO-C90 & 32.3 & 34.8 & 35.7 & 36.3 & 42.0 & 45.5 & 42.6 & $+4.7 \%$ \\
\hline Lung & C34 & 5.3 & 5.5 & 6.7 & 7.4 & 7.5 & 10.5 & 8.9 & $+9 \%$ \\
\hline Colon-rectum & C18-C20 & 3.2 & 2.6 & 4.8 & 4 & 4 & 5.1 & 6 & $+11 \%$ \\
\hline Nasopharynx & C11 & 5.1 & 4.3 & 2.8 & 3 & 3.3 & 3.6 & 2.6 & $-10.6 \%$ \\
\hline Prostate & C61 & 3.1 & 2.6 & 2.5 & 1.8 & 4.3 & 3.7 & 4.3 & $+5.6 \%$ \\
\hline
\end{tabular}

CR crude incidence rate per 100,000; APC annual percent change

finally day laborer $(0.9 \%)(p<0.001)$ (Table 4$)$. Moreover, the majority of patients did not have health insurance $(85.3 \%$ of cases) (Table 4$)$.

\section{Discussion}

Cancer is one of the major health problems worldwide [1, $4,5]$. Hence, it is very important to conduct epidemiological studies to identify risk factors and to develop programs for cancer control and prevention. In Western countries, the risk of cancer increases with age, and therefore, individuals aged 65 and over have the highest incidence rates [23]. In addition, because of early diagnosis and more effective treatments, there have been notable improvements in survival for most cancers [23]. Unlike Western countries, cancer seems to affect a younger population in our study. The most affected age group by cancer was 45-54 years, which accounted for $27 \%$ of cases, and the mean age of patients diagnosed with cancer was 54.1 years. It is important to mention that childhood cancer ( $0-14$ years) accounted for only $0.5 \%$ of all cancers, and were under-represented in this study because the Regional Oncology Center typically manages adult cancer patients. Therefore, the age of occurrence of cancer in Eastern Morocco may be even younger. This finding is consistent with our recently published report on caner prevalence in Eastern Morocco [14].

In our study, the mean age of patients diagnosed with cancer was higher in men than in women (58.1 years versus 52.1 years). This indicates that women are affected by cancer at a younger age than men $(p<0.001)$. Similar results were observed with the Moroccan populations of Casablanca, Rabat and Fez [8, 12, 24, 25].

As shown in Table 1, the sex ratio observed in our study is much higher than that reported in Casablanca,
Rabat and Fez, as well as in other countries in North Africa, Asia, Europe and USA [8, 9, 12, 23, 25-28]. Moreover, the crude incidence observed in 2012 was higher in females than males (80.3 per 100,000 women versus 42.6 per $100,000 \mathrm{men})$. Since the structure of the population of Eastern Morocco showed a sex ratio of female to male of 1.06 during the study period 2006-2012 [13], these data suggest that in Eastern Morocco, women are more affected by cancer than men, which is in agreement with our recently published report on caner prevalence in Eastern Morocco [14]. This great difference in incidence between men and women can be explained by differences in lifestyle, and/or the willingness to treat cancer between men and women.

Our retrospective analysis showed that for both sexes combined and for all cancer sites, breast cancer was the commonest followed by cervix uteri, colon-rectum, lung, nasopharynx, and stomach cancers. In males, lung cancer ranked first, followed respectively by colon-rectum, nasopharynx, prostate, and stomach cancers. Among the females, breast cancer was the most frequent, followed respectively by cervix uteri, colon-rectum, ovarian, and stomach cancer. These distribution patterns of cancers are quite different from those observed in Rabat and Casablanca registries $[10,11,29]$. For example, in females, the thyroid cancer was the third most common cancer in Rabat and Casablanca, while it was ranked at the eighth position in our study $[10,11]$. Similarly, in men, prostate cancer was the second most common cancer in Rabat and Casablanca while it was ranked at the fourth position in our study $[10,11]$. In this study, we found that incidence rates for most cancers are rising in Eastern Morocco. Indeed, the crude incidence rate for all cancers combined has increased from 56.6 to 80.3 per 100,000 per year in 


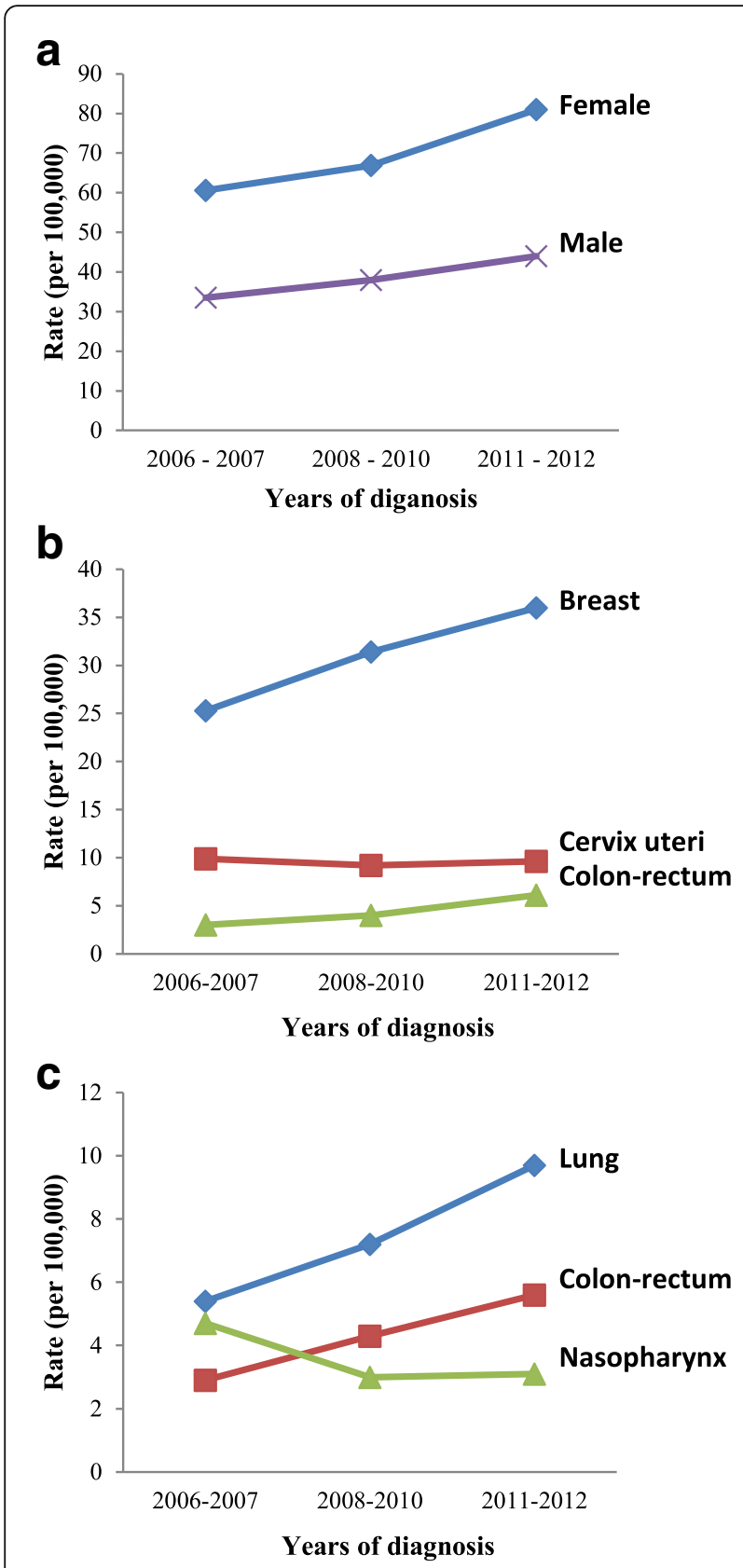

Fig. 2 Trends in crude incidence rates in Eastern Morocco for: a. all cancers combined by sex. $\mathbf{b}$. the top three leading sites in females. c. the top three leading sites in males

females and from 32.3 to 42.6 per 100,000 per year in males during the 2006-2012 period.

Breast cancer was the most common cancer in Eastern Morocco, with a mean age at diagnosis of 48.7 years \pm 11 .4. This result is similar to that observed in the cancer registries of Casablanca (48.1-49.5 years \pm 11.3 ) [29, 30]. However, a different picture is observed in Western countries where breast cancer affects older women [31, 32]. The CR of breast cancer has increased from 2006 to
2012 in Eastern Morocco (23 to 36.8 per 100,000). This rising in trend may be explained by the breast cancer national screening program which has been adopted in Morocco for the period 2010-2019 in the context of the National Cancer Prevention and Control Plan [33]. However, there has been a significant increase in the trend before the program had been implemented (20062008), suggesting that this rising in trend for breast cancer is linked to one or more of the known risk factors for breast cancer. It is possible that some of the increase is related to declines in fertility, since the number of births has declined from 4.5 in 1987 to 2.2 in 2010 [34]. The rising in trend may also be related to later age marriage, since the mean age at marriage of women has steadily increased from 22.2 years in 1982 to 26.6 in 2010 [34]. Several other risk factors could be involved in the trend, like changes in diet, physical activity, lifestyle, genetic factors, age of menarche, exposure to hormones and breastfeeding.

Colon-rectum cancer was the second most common cancer in males and the third in females in Eastern Morocco. The CR of colon-rectum cancer has increased from 2006 to 2012 in Eastern Morocco in both sexes. This rising incidence trends for colon-rectum cancer may be linked to changes in dietary habits. Indeed, it has been well established that a high calorie diet and rich in animal fats, mostly absorbed in the form of red meat, and with few vegetables and fiber, is associated with an increased risk of colon-rectum cancer. Alcohol and smoking also increase the risk for colon-rectum cancer [35-37]. Conversely, a diet providing little fat, lots of vegetables and possibly rich in fiber, has a protective effect [38-42]. In Eastern Morocco, there is still no screening program for colon-rectum cancer. Therefore, the observed rising incidence trend in this cancer in both males and females justifies the need to establish programs for colon-rectum cancer control and prevention in Eastern Morocco.

Lung cancer was the most common cancer in males in Eastern Morocco. The incidence of Lung cancer in males has increased from 2006 to 2012 in Eastern Morocco (5.3 to 8.9 per 100,000$)$. Lung cancer is the leading cancer in males in developing countries. However, it ranks second after prostate cancer in Europe [43]. This is also the leading cause of cancer death [44]. The association between lung cancer and smoking is well established [45-47]. Therefore, the observed rising incidence trend in lung cancer in Eastern Morocco may be linked to the increase in the prevalence of smoking $[48,49]$. Thus, it is important to develop tobacco control measures as soon as possible to avoid future increases in lung cancer in Eastern Morocco.

Nasopharynx cancer was the third most common cancer in males and the sixth among women in Eastern Morocco. In both sexes, nasopharynx cancer has shown a steady decline in incidence throughout the study period. This 


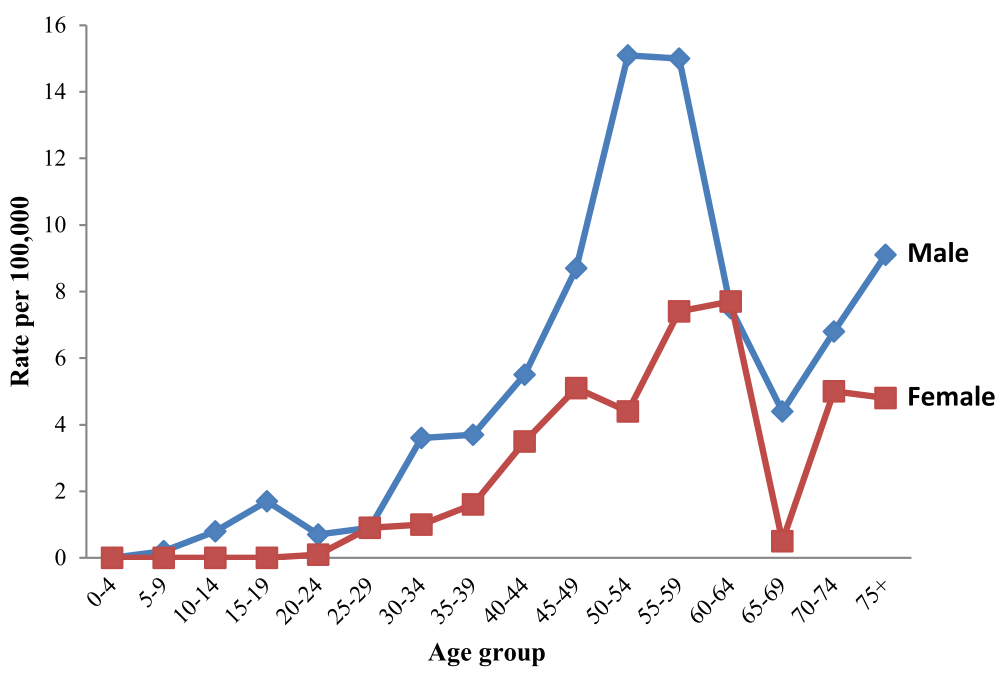

Fig. 3 Age-specific incidence rates of nasopharynx cancer in Eastern Morocco

decreasing trend can be linked to changes in diet, lifestyle or exposure to toxic smoke. Indeed, the association between nasopharynx cancer and smoking, working in conditions with poor ventilation, infection with Epstein Barr virus, and the rich traditional food preservatives has been demonstrated [50-53]. In males, the age-specific incidence rate of nasopharynx has shown a bimodal distribution with the first peak in children (15-19 years), and the second peak in adults (age group 50-59 years). This result is similar to that observed in the cancer registry of Setif in Algeria (two peaks at $15-24$ and 50-59 years) [54] . However, a different picture is observed in the cancer registry of Casablanca, where the first peak was observed earlier (10-14 years age group) [11, 22, 54]. This difference may

Table 4 Socio-demographic structure of the incident cancer cases in Eastern Morocco, October 2005-December 2012

\begin{tabular}{lll}
\hline & $\mathrm{N}$. & $\%$ \\
\hline Place of residence & 6,198 & 78.7 \\
Urban & 1,674 & 21.3 \\
Rural & & \\
Employment status & 272 & 3.5 \\
Employed & 324 & 4.2 \\
Self-employed & 6,398 & 83.4 \\
Unemployed & 388 & 5.1 \\
Retired & 140 & 1.8 \\
Farmer & 82 & 1.1 \\
Student & 71 & 0.9 \\
Day laborer & & 85.3 \\
Health Insurance status & 6,571 & 14.7 \\
Without health insurance & 1,134 & \\
With health insurance &
\end{tabular}

$\mathrm{N}$ number of incident cases with known information; \% be explained by the under-representation of childhood cancer in this study because the ROC typically manages adult cancer patients. In females, the incidence rate increased gradually with age and reached a peak in the 5564 years age group. Such a finding is different from the one reported in Casablanca, where the age-specific incidence rate showed that the incidence rate reached a peak in adults at an earlier age group (40-44 years) [11, 22, 54]. These differences may be explained by a lower prevalence of smoking among females in Eastern Morocco compared to Casablanca. Further studies are needed to determine the causes of these differences.

Cancers are caused by several factors, including genetic, geographical, socioeconomic, and cultural factors [55-57]. Thus, the epidemiological characteristics of cancer vary from one region to another, and even within the same country. In Tunisia, for example, cancer registries of Sousse, Sfax and northern Tunisia have shown quite different cancer incidence rates [22]. Similarly, the data presented here on cancer patterns in Eastern Morocco are different from those of the Casablanca and Rabat cancer registries [10,29]. The low socioeconomic status could in part explain the general increase in the incidence of cancer of most major sites in Eastern Morocco during the study period. Indeed, $79 \%$ of incident cancer cases registered at the Regional Oncology Center were from urban areas and 21\% from rural areas $(p<0.001)$. Moreover, $83 \%$ of patients were unemployed and $85 \%$ have no health insurance. It is worth noting that according to the High Commission for Planning, the employment rate for women in eastern Morocco is only $11.1 \%$, compared to $65.7 \%$ for men [58]. Therefore, men may be at lower risk due to engaging in occupations requiring greater physical activity. Although occupational differences may explain some of the sex difference, other factors such as diet and hormonal differences must be considered. 


\section{Conclusion}

In the absence of a cancer registry in Eastern Morocco, it is difficult to understand the epidemiology of this disease and develop programs for cancer control and prevention. Since Hassan II Regional Oncology Center was the only specialized cancer hospital for cancer management in Eastern Morocco during the study period, these results are of great value and provide a valuable tool for cancer control and prevention in Eastern Morocco. Our results confirm the gravity of this problem, and provide epidemiological knowledge about cancer which is necessary for health care planning. This work is of great interest to the health system since any prevention policy cannot be implemented without epidemiological studies and very thorough statistical analysis. Indeed, the rates of many cancers are rising and require the development of effective programs for cancer control and prevention. A better and easier access to cancer care is a priority, given that the majority of patients who are treated in the Regional Oncology Center are unemployed, and do not have medical care coverage. It is also essential to initiate the establishment of a regional cancer registry to allow the surveillance of cancer trends and to plan a program for cancer control and prevention in Eastern Morocco.

\section{Abbreviations \\ APC: Annual percent change; CR: crude incidence rates; HCP: High Commission for Planning; HM: hematological malignancies.; IARC: International Agency for Research on Cancer; ICD-O: International classification of diseases for Oncology; ROC: Hassan II Regional Oncology Center; WHO: World health organization}

\section{Acknowledgments}

We are grateful to the clinical team and to all administrative staff at the Hassan II Regional Oncology Center of Oujda for their support. We thank the president of Mohammed Premier University, Dr. M. Benkaddour, and the Regional Director of the Ministry of Health in Eastern Morocco for their support. We are grateful to Dr. A. Azzouzi and all the administrative staff of the Faculty of Medicine and Pharmacy of Oujda for their valuable support and encouragement throughout the entire work.

\section{Funding}

No funding was received for this study.

\section{Availability of data and materials}

The datasets used and/or analyzed during the current study are available from the corresponding author on reasonable request.

\section{Authors' contributions}

Manal EE, Mounia EE, MO, RB and MB conceived and designed the study. Manal EE, Mounia EE and MB carried out the analysis. Manal EE and MB drafted the initial manuscript. All authors contributed to the writing of the manuscript, read and approved the final manuscript.

\section{Ethics approval and consent to participate}

Our study protocol was ethically approved by the Ethical Review Committee for Biomedical Research of the Faculty of Medicine and Pharmacy of Casablanca under the number 41/14. In this study, because obtaining informed consent was not possible, we were granted a waiver of consent by the Ethical Review Committee. Patient records/information was anonymized and de-identified prior to analysis. The authorization for personal data processing was obtained from the National Commission of control of Personal Data Protection under the number A-RS-280/2014).

\section{Consent for publication}

Not Applicable.

\section{Competing interests}

The authors declare that they have no competing interests.

\section{Publisher's Note}

Springer Nature remains neutral with regard to jurisdictional claims in published maps and institutional affiliations.

Received: 29 April 2016 Accepted: 23 August 2017

Published online: 29 August 2017

\section{References}

1. Ferlay J, Soerjomataram I, Dikshit R, Eser S, Mathers C, Rebelo M, et al. Cancer incidence and mortality worldwide: sources, methods and major patterns in GLOBOCAN 2012. Int J Cancer. 2015;136(5):E359-86. https://doi. org/10.1002/ijc.29210.

2. Gulland A. Global cancer prevalence is growing at "alarming pace," says WHO. BMJ. 2014;348:g1338.

3. Ma X, Yu H. Global burden of cancer. Yale J Biol Med. 2006;79(3-4):85-94.

4. Bray F, Jemal A, Grey N, Ferlay J, Forman D. Global cancer transitions according to the human development index (2008-2030): a populationbased study. Lancet Oncol. 2012;13(8):790-801.

5. IARC. World cancer factsheet. London: Cancer Research UK; 2014. http:// publications.cancerresearchuk.org/downloads/Product/CS_REPORT_WORLD.pdf

6. Jemal A, Bray F, Center MM, Ferlay J, Ward E, Forman D. Global cancer statistics. CA Cancer J Clin. 2011;61(2):69-90.

7. Sante en chiffres. Ed 2013. Maroc: Ministère de la Santé; 2012. Available from http://www.sante.gov.ma/Publications/Etudes_enquete/Documents/ Sante\%20en\%20chiffres\%202012_Edition\%202013.pdf.

8. Tazi MA, Er-Raki A, Benjaafar N. Cancer incidence in Rabat, Morocco: 20062008. Ecancermedicalscience. 2013;7:338. https://doi.org/10.3332/ecancer. 2013.338. Print 2013.

9. Sahraoui S, Benider A, Bennani OM, Karkouri M, Ennaji H, Kotb S, et al. Incidence cancer in Casablanca region in 2004: first results from the greater Casablanca cancer registry (GCCR). Int Res J. 2013;1(3):35-45.

10. RECRAB: Cancer registry Rabat, 2005 (French). 2009. http://www.irc.ma/pdf statistique/Registre-des-Cancers-de-Rabat.pdf.

11. RCRC: Cancer registry of the great Casablanca region 2005-2007 (French). 2012. http://contrelecancer.ma/en/documents/categorie/publications-3/.

12. Bouchbika Z, Haddad H, Benchakroun N, Eddakaoui H, Kotbi S, Megrini A, et al. Cancer incidence in Morocco: report from Casablanca registry 2005-2007. Pan Afr Med J. 2013;16:31.

13. HCP: Monograph of the region of Eastern Morocco 2012 (French): Oujda Regional Direction 2012. http://www.hcp.ma/regionoriental/docs/ monographieFr2012/monographie\%202012.pdf.

14. Elidrissi Errahhali M, Elidrissi Errahhali M, Abda N, Bellaoui M. Exploring geographic variability in cancer prevalence in eastern Morocco: a retrospective study over eight years. PLoS One. 2016;11(3):e0151987. https:// doi.org/10.1371/journal.pone.0151987.

15. Elidrissi Errahhali M, Elidrissi Errahhali M, Boulouiz R, Ouarzane M, Bellaoui M. Distribution and features of hematological malignancies in eastern Morocco: a retrospective multicenter study over 5 years. BMC Cancer. 2016; 16(1):1-10.

16. Elidrissi Errahhali M, Elidrissi Errahhali M, Ouarzane M, El Harroudi T, Afqir S, Bellaoui M. First report on molecular breast cancer subtypes and their clinico-pathological characteristics in eastern Morocco: series of 2260 cases. BMC Womens Health. 2017;17:3.

17. Fritz A, Percy C, Jack A, Shanmugaratnam K, Sobin L, Parkin DM et al: International classification of diseases for oncology. Geneva: World Health Organization; 2008. ISBN: 9789242545340.

18. Percy C, Van Holten V, Muir C. International classification of diseases for oncology (ICD-O). Geneva: World Health Organization; 1990.

19. Curado M-P, Edwards B, Shin HR, Storm H, Ferlay J, Heanue M, et al. Cancer incidence in five continents, volume IX. France: IARC Press; 2007. isbn: 9283221605.

20. Parkin D, Whelan S, Ferlay J, Raymond L, Young J: Cancer incidence in five continents Vol. VII., vol. 19. Lyon: IARC Scientific Publications; 2000. ISBN: 92 83221435 . 
21. Chen J-G, Zhu J, Parkin DM, Zhang Y-H, Lu J-H, Zhu Y-R, et al. Trends in the incidence of cancer in Qidong, China, 1978-2002. Int J Cancer. 2006;119(6): 1447-54.

22. Missaoui N, Trabelsi A, Parkin DM, Jaidene L, Chatti D, Mokni M, et al. Trends in the incidence of cancer in the Sousse region, Tunisia, 1993-2006. Int J Cancer. 2010;127(11):2669-77.

23. Belot A, Grosclaude P, Bossard N, Jougla E, Benhamou E, Delafosse P, et al. Cancer incidence and mortality in France over the period 1980-2005. Rev Epidemiol Sante Publique. 2008:56(3):159-75

24. Ibrahim A, Mikhail NNH, Khaled H, Baraka H, Abdeen M, Bishara A et al: Cancer profile in Aswan. Egypt. Methodology and results chart book 2008. Cairo, Egypt National Cancer Registry; 2010 http://www.mcit.gov.eg/Upcont/ Documents/Final\%20Chart\%20Book20105611283.pdf

25. Chbani L, Hafid I, Berraho M, Mesbahi O, Nejjari C, Amarti A. Epidemiological and pathological features of cancer in fez Boulemane region, Morocco. East Mediterr Health J. 2013;19(3):263-70.

26. Fouatih Z, Midoun N, .Ammour F, Lahouel O, Mokhtari L: The cancer registry of Oran. Ten years of registration: 1996-2005. Oran, University of Oran, Faculty of Medicine,. 2008. http://tethys.univ-amu.fr/sites/tethys.univ-amu.fr/ files/reunion/cancer_1996___2005_z._fouatih.pdf.

27. Sellami A, Boudawara TS, Hsairi M, Jlidi R, Achour N: Incidence des cancers dans le gouvernorat de Sfax. 2007. http://www.emro.who.int/images/stories/ tunisia/documents/incidence_des_cancers_dans_le_gouvernorat_de_sfax_ 2000-2002_Ahmed_SellamiMohamed_Hsairi.pdf

28. Chokunonga E, Levy L, Bassett M, Mauchaza B, Thomas D, Parkin D. Cancer incidence in the African population of Harare, Zimbabwe: second results from the cancer registry 1993-1995. Int J Cancer. 2000;85(1):54-9.

29. RCRC: Cancer registry of the greater Casablanca region 2004 (French). 2004. http://contrelecancer.ma/en/documents/categorie/publications-3/.

30. CRGC: Cancer registry of the greater Casablanca region 2005-2007 (French). 2012. http://contrelecancer.ma/en/documents/categorie/publications-3/.

31. Blamey R, Hornmark-Stenstam B, Ball G, Blichert-Toft M, Cataliotti L, Fourquet A, et al. ONCOPOOL-a European database for 16,944 cases of breast cancer. Eur J Cancer. 2010;46(1):56-71.

32. Najjar H, Easson A. Age at diagnosis of breast cancer in Arab nations. Int J Sur. 2010;8(6):448-52.

33. ALSLCC: National Cancer Prevention and control plan 2010-2019. 2009. http://www.contrelecancer.ma/site_media/uploaded_files/PNPCC___Axes_ strategiques_et_mesures_2010-2019.pdf

34. HCP: Communiqué de presse à l'occasion de la journée internationale de la femme 2013. 2013. http://www.hcp.ma/Communique-de-presse-a-loccasion-de-la-journee-internationale-de-la-femme-2013_a1142.html

35. Troche JR, Mayne ST, Freedman ND, Shebl FM, Guertin KA, Cross AJ, et al. Alcohol consumption-related metabolites in relation to colorectal cancer and adenoma: two case-control studies using serum biomarkers. PLoS One. 2016:11(3):e0150962.

36. Inoue M. Association between alcohol consumption and colorectal cancer risk. Current Nutrition Reports. 2013;2(1):71-3.

37. Cross AJ, Boca S, Freedman ND, Caporaso NE, Huang W-Y, Sinha R, et al. Metabolites of tobacco smoking and colorectal cancer risk. Carcinogenesis. 2014;35(7):1516-22. https://doi.org/10.1093/carcin/bgu071.

38. Liang PS, Chen TY, Giovannucci E. Cigarette smoking and colorectal cancer incidence and mortality: systematic review and meta-analysis. Int J Cancer. 2009;124(10):2406-15.

39. Baena R, Salinas P. Diet and colorectal cancer. Maturitas. 2015;80(3):258-64.

40. Maskarinec G, Jacobs S, Harmon BE, Wilkens LR, Le Marchand L, Kolonel LN, et al. Four a priori-defined diet quality indexes and survival among men and women with colorectal cancer: the multiethnic cohort. FASEB J. 2016; 30(1 Supplement):42.2-2

41. Espejo-Herrera N, Gràcia-Lavedan E, Boldo E, Aragonés N, Pérez-Gómez B, Pollán $\mathrm{M}$, et al. Colorectal cancer risk and nitrate exposure through drinking water and diet. Int J Cancer. 2016; https://doi.org/10.1002/ijc.30083.

42. Stepien $M$, Chajes $V$, Romieu I. The role of diet in cancer: the epidemiologic link. Salud Publica Mex. 2016;58(2):261-73.

43. Ferlay J, Shin HR, Bray F, Forman D, Mathers C, Parkin DM. Estimates of worldwide burden of cancer in 2008: GLOBOCAN 2008. Int J Cancer. 2010; 127(12):2893-917.

44. Fitzmaurice C, Dicker D, Pain A, Hamavid H, Moradi-Lakeh M, Maclntyre MF, et al. The global burden of cancer 2013. JAMA Oncol. 2015;1(4):505-27.
45. John $U$, Hanke M. Lung cancer mortality and years of potential life lost among males and females over six decades in a country with high smoking prevalence: an observational study. BMC Cancer. 2015;15(1):1.

46. Thun MJ, Carter BD, Feskanich D, Freedman ND, Prentice R, Lopez AD, et al. 50-year trends in smoking-related mortality in the United States. N Engl J Med. 2013;368(4):351-64. https://doi.org/10.1056/NEJMsa1211127.

47. Chang CM, Corey CG, Rostron BL, Apelberg BJ. Systematic review of cigar smoking and all cause and smoking related mortality. BMC Public Health. 2015;15(1):1.

48. Nejjari C, Benjelloun MC, Berraho M, El Rhazi K, Tachfouti N, Elfakir S, et al. Prevalence and demographic factors of smoking in Morocco. Int J Public Health. 2009;54(6):447-51. https://doi.org/10.1007/s00038-009-0082-2.

49. Ademola O, Kenneth $\mathrm{O}$, Margaret $\mathrm{H}$, Joshua K, Maria C: L'incidence du tabagisme sur la santé et le développement socio-économique en Afrique: état des lieux. 2010. http://www.carmma.org/sites/default/files/PDF-uploads/ Tobacco_Report_FRENCH.pdf

50. Bendjemana K, Satta D, Adjabi K, Miali A, Aiddoudi S, Kadri A. Epidemiology of nasopharyngeal carcinoma and impact of food factors in north east of Algeria (French). African Journal of Cancer. 2011;3(1):59-62. https://doi.org/ 10.1007/s12558-010-0141-x.

51. Busson P, Ooka T, Corbex M. Nasopharyngeal carcinomas and Epstein-Barr virus: from epidemiology and detection to therapy. Med Sci (Paris). 2004; 20(4):453-7

52. Hildesheim A, Wang C-P. Genetic predisposition factors and nasopharyngeal carcinoma risk: a review of epidemiological association studies, 2000-2011: Rosetta stone for NPC: genetics, viral infection, and other environmental factors. Semin Cancer Biol. 2012;22(2):107-16.

53. Bray F, Haugen M, Moger TA, Tretli S, Aalen OO, Grotmol T. Age-incidence curves of nasopharyngeal carcinoma worldwide: bimodality in low-risk populations and aetiologic implications. Cancer Epidemiol Biomark Prev. 2008:17(9):2356-65.

54. Hamdi Cherif M, Zaidi Z, Abdellouche D, Hamdi S, Lakhdari N, Djema Bendjazia A, et al. Cancer registry of Setif (Algeria): cancer incidence, trend and survival, 1986-2005 (French). J Afr Cancer. 2010;2(4):245-58.

55. Sloan FA, Gelband $\mathrm{H}$ : Cancer causes and risk factors and the elements of cancer control. 2007. Available from: http://www.ncbi.nlm.nih.gov/books/ NBK54025/.

56. Nagrani R, Mhatre S, Boffetta P, Rajaraman P, Badwe R, Gupta S, et al. Understanding rural-urban differences in risk factors for breast cancer in an Indian population. Cancer Causes Control. 2016;27(2):199-208.

57. Alderton GK. Cancer risk: debating the odds. Nat Rev Cancer. 2016;16(2):68. https://doi.org/10.1038/nrc.2016.5.

58. HCP: Moroccan Women and Labor Market: Characteristics and Evolution (French). 2013. http://www.hcp.ma/Femmes-Marocaines-et-Marche-duTravail-Caracteristiques-et-Evolution_a1367.html

\section{Submit your next manuscript to BioMed Central and we will help you at every step:}

- We accept pre-submission inquiries

- Our selector tool helps you to find the most relevant journal

- We provide round the clock customer support

- Convenient online submission

- Thorough peer review

- Inclusion in PubMed and all major indexing services

- Maximum visibility for your research

Submit your manuscript at www.biomedcentral.com/submit 